\title{
KEBUDAYAAN DAN SINKRETISME TERHADAP PEMBENTUKAN RUANG SERTA BENTUK RUMAH TRADISONAL TOLOTANG KABUPATEN SIDRAP
}

\author{
Aris Alimuddin ${ }^{1}$ \\ ${ }^{1}$ Jurusan Arsitektur Fakultas Teknik Universitas Muslim Indonesia
}

\begin{abstract}
Abstrak
Arsitektur sebagai hasil karya seni budaya diakui sebagai salah satu wujud kebudayaan yang dapat dijadikan cerminan dari kehidupan manusianya, dari masa ke masa. Arsitektur sebagai unsur kebudayaan, laksana salah satu bentuk bahasa "non-verbal" manusia yang bernuansa simbolik. Penelitian ini bertujuan untuk mengetahui sampai sejauh mana pengaruh kebudayaan dan sinkretisme terhadap pembentukan ruang serta bentuk rumah tradisional Tolotang di Kabupaten Sidrap. Jenis penelitian ini adalah kualitatif dengan metode bersifat deskriptif. Metode pengambilan data dengan observasi langsung, wawancara mendalam, sketsa dan dokumentasi. Obyek penelitian adalah unit rumah komunitas Hindu Towani Tolotang. Hasil penelitian objek penelitian adalah unit rumah Bugis komunitas Hindu Towani Tolotang. Hasil penelitian menunjukkan adanya perubahan bentuk yang terjadi pada bagian kolom rumah dan penggabungan dua rumah menjadi satu. Sedangkan pada ruang secara simbolis terbagi atas tamping (serambi) yang membagi antara rumah induk dan rumah tambahan. Disimpulkan bahwa dengan adanya kebudayaan dan sinkretisme pada komunitas Hindu Towani Tolotang menimbulkan pengaruh yang berbeda terutama pada bentuk dan ruangnya.
\end{abstract}

Kata Kunci : Kebudayaan, sinkretisme, ruang, bentuk

\begin{abstract}
Architecture as result of the culture refined creation has been avowed as one of culture form which accomplised as reflection from human life, from time to time.Architecture as subtance of culture like as one for leanguage form "non-verbal" human nuaced symbolic. purpose of this detailed examination si to find out as for as culture and sinkretism influence toward shape establish ment with tradisional Tolotang district. Sidrap house form. The sort of this researchis qualitative methode and discriitive character. Data removal methode with direct observation, deep interview, sketch and documentation. The object research is unit house hindu Towani Tolotang comunity house. Result of the object research is unit bugis house hindu Towani Tolotang community.Result of research is unit bugis house hindu towani tolotang comunity house.result of the resarch show any transformation accure in in house column part and 2 combination house as one meanwhile in space as simbolic split into front porch which divide between main house and addition house.Concluded that by culture and sinkretism in derection to hindu Towani Tolotang cause different effect especially on the shappe and it space.
\end{abstract}

Keyword : Culture, Sikretism, Space, Shape (form)

\section{PENDAhuluan}

Keterkaitan hubungan antara kebudayaan suatu bangsa dengan arsitektur, tergambar pada telaah masing-masing unsurnya. Telaah arsitektur pada umumnya berpijak pada unsur-unsur "konsep", cara "membangun" dan "wujud nyata" dari "bangunan" sebagai suatu lingkungan buatan dalam rekayasa lingkungan sekitarnya. Telaahan "kebudayaan" selalu berpijak pada unsur-unsur buah pikiran "idea", perbuatan, sikap dan prilaku "behavior" serta hasil karya seni "artefak".

Rumah adalah kebudayaan fisik, yang dalam konteks tradisional merupakan bentuk ungkapan yang berkaitan erat dengan kepribadian masyarakatnya. Ungkapan fisiknya sangat dipengaruhi oleh faktor sosio-kultural dan lingkungan dimana ia tumbuh dan berkembang. Perbedaan wilayah dan latar belakang budaya akan menyebabkan perbedaan pula dalam ungkapan arsitekturnya

Komunitas Towani Tolotang ini menarik untuk diteliti karena menganut sistem sosial dari konsep kepercayan yang mereka pahami yang menjadikannya sebagai dasar dari pola kehidupan sosial bermasyarakat dan sebagai tolak ukur tentang baik dan buruknya dalam kehidupan sosial. Terlepas dari dinamika komunitas ini yang selalu didera sinisme dan dianggap kolot, mereka tetap bertahan dengan pemahaman mereka. Mereka masih menjaga kepercayaannya sebagai tanda setianya pada agama leluhurnya, mereka tetap bertahan, tidak tunggal, bukan satu-satunya yang bertahan di Amparita karena beberapa wilayah lain di Kabupaten Sidenreng Rappang kepercayaan seperti ini masih bertahan. 


\section{Budaya}

Menurut Koentjaraningrat (1974), menyatakan bahwa kebudayaan terdiri atas tiga wujud :

1. Wujud kebudayaan sebagai suatu kompleks dari ide-ide, gagasan, nilai-nilai, norma dan peraturan.

2. Wujud kebudayaan sebagai suatu kompleks aktivitet kelakuan berpola dari manusia dalam masyarakat.

3. Wujud kebudayaan sebagai benda-benda hasil karya manusia.

Wujud pertama adalah wujud yang ideal dari kebudayaan. Sifatnya abstrak, tak dapat diraba. Lokasinya ada dalam alam pikiran dari warga masyarakat dimana kebudayaan yang bersangkutan itu hidup. Kebudayaan ideal ini dapat kita sebut adat tata kelakuan, atau adat istiadat dalam bentuk jamaknya.

Wujud kedua dari kebudayaan yang sering disebut sistem sosial, menganai kelakuan berpola dari manusia itu sendiri. Sistem sosial ini terdiri dari aktivitas-aktivitas manusia yang berinteraksi, berhubungan serta bergaul satu dengan lain menurut pola-pola tertentu yang berdasarkan adat tata kelakuan.

Wujud ketiga dari kebudayaan disebut kebudayaan fisik, yaitu berupa seluruh total dari hasil fisik dan aktivitas, perbuatan dan karya semua manusia dalam masyarakat.

Kerangka kebudayaan merupakan dimensi analisis dari konsep kebudayaan yang dikombinasikan ke dalam suatu bagan lingkaran yang ditujukan untuk menunjukkan bahwa kebudayaan bersifat dinamis.

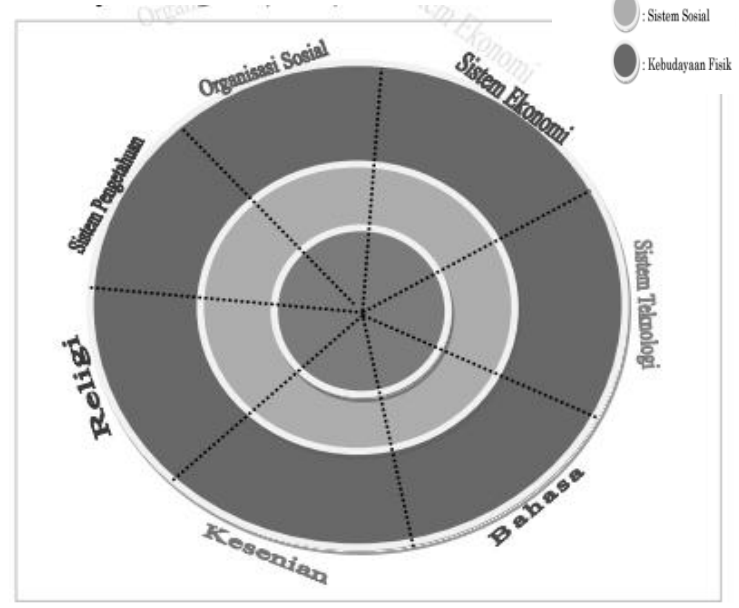

Gambar 1. Kerangka Budaya menurut Koentjaraningrat (1985) dalam Ig. Dodiet Aditya Setyawan, SKM, MPH.

Adapaun pembagian lingkaran menjadi 7 (Tujuh) bagian adalah melambangkan 7 Unsur Kebudayaan Universal menurut konsep B. Malinowski. Ketujuh Unsur Kebudayaan Universal tersebut dapat mempunyai Tiga Wujud Kebudayaan, yaitu :
1. Sistem Budaya,

2. Sistem Sosial, dan

3. Kebudayaan Fisik

Jadi, menurut konsep B. Malinowski, kebudayaan di dunia mempunyai 7 (Tujuh) Unsur Universal, yaitu:

1. Bahasa .

2. Sistem Teknologi

3. Sistem Ekonomi / Mata Pencaharian

4. Organisasi Sosial

5. Sistem Pengetahuan

6. Religi

7. Kesenian

\section{Sinkretisme}

Secara etimologis, sinkretieme berasal dari kata syin dan kretiozein atau kerannynai yang berarti mencampurkan elemen-elemen yang saling bertentangan. (Sumanto al-Qurtubi, 2016).

Adapun beberapa defenisi sinkretisme antara lain :

1. Resse,W,I.,(1980). Syncretism; froom the greek "Synkretizein" (to combine). A term introduced by Plutarcht to characterize the harmonizing efforts of the Neaplotonists. The term refers to the blending of pholosophical doctrines from opposing school, or relegius doctrines from different faith, in an effort to again a unified point of view in philosophy the term is usually pejorative, and the mixture of doctrines undistinguished, common opinion being that superficialy is bound to result of syncretism.

2. (B.Lorens, Kamus Filsafat. 1996). Sinkretisme adalah penyatuan atau upaya penyatuan ideologiideologi yang bertentangan kedalam suatu kesatuan pikiran atau ke dalam suatu hubungan sosial yang harmonis.

3. (E.jhon.M,S, Hasan. 1976). Syncretism diartikan sebagai penyatuan aliran.

4. (Kamus Besar Bahasa Indonesia. 1988). Sinkretisme adalah paham (aliran) baru yang merupakan perpaduan dari beberapa paham (aliran) yang berbeda untuk mencari keserasian, keseimbangan dan sebagainya.

5. (Cross,F.L.1997). Syncretism; The attempt to combine different or opposite doctrins and practices. Especeally in reference to philosopical and religious system.The term came into prominence in the the 17 th century, when it was applied to the teaching of G. Calixtus, who undertook to unite the reformation Churces in Germany with the Catholic Church on the basis of the Apostles creed and the doctrine of the first centuries. It is also frequently applied to the unifying cultural forces in the mediterranean civilzation of the Hellenistic and roman periods, an in the history of religion to any fusion of varios beliefs and practices.e.q tosome tendencies in pre-Cristian Judaism. In the RC theology of grace in the term is used of attemps to combine Thomist and Molinist teaching. 


\section{Ruang Dalam Arsitektur}

Ruang dalam arsitektur dapat diartikan sebagai pelingkup suatu kegiatan, sedangkan bentuk adalah kenampakan atau raut dari suatu ruang. Sehingga raut atau kenampakan suatu ruang juga akan dipengaruhi oleh besaran ruang, skala dan kegiatan apa yang akan diwadahi oleh suatu ruangan.

Menurut Johara T. Jayadinata, ruang merupakan tempat interaksi masyarakat dalam kaitannya dengan kehidupan sosial dan kemasyarakatannya, dalam hal ini ruang bisa dikatakan sebagai wadah untuk menyalurkan berbagai aktivitas baik sosial, ekonomi, dan budaya masyarakat dimana terjadi percampuran kegiatan, strata sosial, dan budaya masyarakatnya.

Bentuk ruang, baik ruang luar dan atau ruang dalam yang spesifik juga menentukan identitas bangunan. Dikatakan oleh G.H Broadbent dalam bukunya ; Design In Architecture, dengan mengutip pernyataan dari ahli palaeoantropologi Henri Breuil, yang berbunyi 'Para pelukis gua di jaman es, menggambar bentuk-bentuk rekaan dari alam mereka, seperti binatang dan tumbuhan, atau kegiatan mereka, dan dengan adanya bentuk-bentuk itu, mereka ingin menunjukkan kemampuan meniru (analogi) mereka dan menjadikan mereka lebih maju dari yang lain'. Dari pernyataan di atas dapat ditarik kesimpulan, ruang dan bentuk telah lama digunakan manusia sebagai identitas dan penanda arsitektur, dari yang paling primitif hingga yang paling modern, baik secara umum, maupun dalam ruang lingkup tertentu.

\section{Bentuk Dalam Arsitektur}

Beberapa pengertian bentuk dalam arsitektur

- Suatu perwujudan dan organisasi ruang yang merupakan hasil dari suatu proses pemikiran yang didasarkan atas pertimbangan fungsi dan usaha pernyataan diri / ekspresi (Hugo Haring).

- Wujud dari penyelesaian akhir konstruksi yang pengertiannya sama (Mies Van Der Rohe).

- Suatu keseluruhan dan fungsi-fungsi yang bekerja secara bersamaan, yang hasilnya merupakan hasil dipenuhinya syarat syarat kokoh, guna dan indah. (Vitruvius).

Ciri-ciri visual bentuk menurut Ching (1996 : 5051), adalah :

- Wujud adalah ciri-ciri pokok yang menunjukkan bentuk yang merupakan hasil konfigurasi tertentu dari permukaan-permukan dan sisi suatu bentuk

- Dimensi adalah panjang, lebar dan tinggi dimana dimensi-dimensi ini yang menentukan proporsinya.

- Warna adalah corak, intensitas dan nada pada permukaan suatu bentuk yang merupakan atribut yang paling menyolok yang membedakan satu bentuk terhadap lingkungannya. Warna juga mempengaruhi bobot visual suatu bentuk. pertanyaan penlitian berdasarkan latar belakang di atas, maka permasalahan yang dibahas dapat dirumuskan sebagai berikut :

a Bagaimana pengaruh kebudayaan terhadap pembentukan ruang pada rumah tradisional tolotang.

b Bagaimana pengaruh sinkretisme terhadap pengembangan fungsi ruang dan bentuk rumah tinggal masyarakat tolotang.

\section{Metode, Hasil dan Pembahasan}

a. Metode

Penelitian ini merupakan penelitian analitik deskriptif. Penelitian ini dimulai dari pengamatan langsung di lapangan serta melakukan analisis obyek dan sekitarnya secara teliti serta sistematis. Hasil data akan didistribusikan dalam bentuk gambar, grafik dan tabel yang selanjutnya dilakukan analisis data.

Obyek penelitian ini berada di Kecamatan Amparita Kelurahan Amparita, Kabupaten Sidrap dan sekitarnya.

Pengambilan dan pengumpulan data di lapangan akan dilakukan dengan 2 (dua) tahap yaitu :

1) Pada tahap pertama adalah pengumpulan data berupa gambar bangunan pada obyek penelitian yaitu gambar tatanan ruang bangunan rumah warga Tolotang di sekitarnya yang berupa fisik bangunan dan di luar bangunan.

2) Tahap kedua dilakukan setelah selesai tahap pertama, maka dilakukan pencatatan data dengan wawancara langsung dan dokumentasi.

3) Data yang diperoleh pada penelitian ini bersumber dari data primer dan data sekunder. Data primer yaitu data yang didapatkan dari dokumentasi dan pencatatan langsung di lapangan yakni bentuk bangunan dan sekitarnya dengan wawancara dan dokumentasi. Sedangkan data sekunder merupakan pendukung dengan referensi yang dianggap relevan dengan permasalahan dalam penelitian ini.

\section{b. Hasil dan Pembahasan}

\section{Lokasi Penelitian}

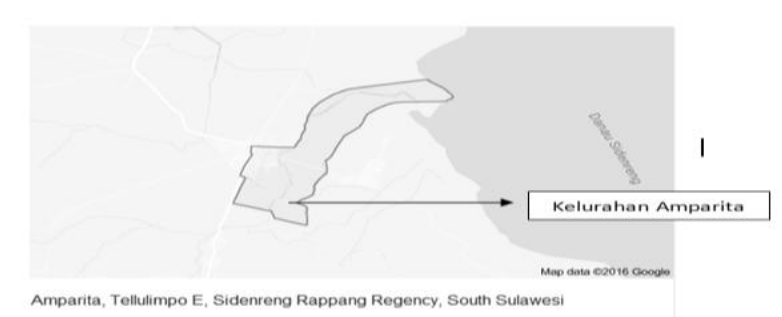

Gambar 2. Peta Wilayah Kelurahan Amparita

Sumber: http://www.sidrapkab.go.id/ (diakses 7 September 2016)

Berdasarkan Data Profil Kelurahan Tahun 2014, Kelurahan Amparita terletak di sebelah 
Selatan Kabupaten Sidenreng Rappang (Sidrap) dengan luas wilayah $3,93 \mathrm{~km}^{2}$. Jarak Kelurahan Amparita dari ibukota Kabupaten Sidrap yaitu 9 km, serta 228 km dari ibukota Provinsi Sulawesi Selatan. Adapun batas administrasi Kelurahan Amparita, yaitu:

a. Sebelah Utara berbatasan dengan Kelurahan Arateng.

b. Sebelah Timur berbatasan dengan Desa Teteaji.

c. Sebelah Selatan berbatasan dengan Kelurahan Pajalele.

d. Sebelah Barat berbatasan dengan Kelurahan Todang Pulu dan Kelurahan Baula.

\section{Analisis Pengaruh Kebudayaan Terhadap Pembentukan Ruang Rumah Tolotang \\ Rumah adalah wadah dari ekspresi gaya hidup} dimana komponen dari gaya hidup tersebut merupakan gabungan dari konsep kebudayaan, etika, karakter dan pandangan hidup penghuninya (Rapoport, 1969). Rumah selalu didesain dan dibangun dengan tradisi tertentu dengan pola yang mencerminkan pola atau cara penghuninya tinggal (Friedmann dkk, 1970). Elemen pengisi ruang beserta pola penyusunannya pun disusun atas dasar tradisi tersebut sehingga tercipta interior yang harmonis antara kebutuhan dengan struktur yang melingkupi (Friedmann dkk, 1970). Pembangunan rumah merupakan fenomena kebudayaan dimana bentuk fisik dan organisasi ruangnya sangat dipengaruhi oleh kebudayaan penghuni (Rapoport, 1969).

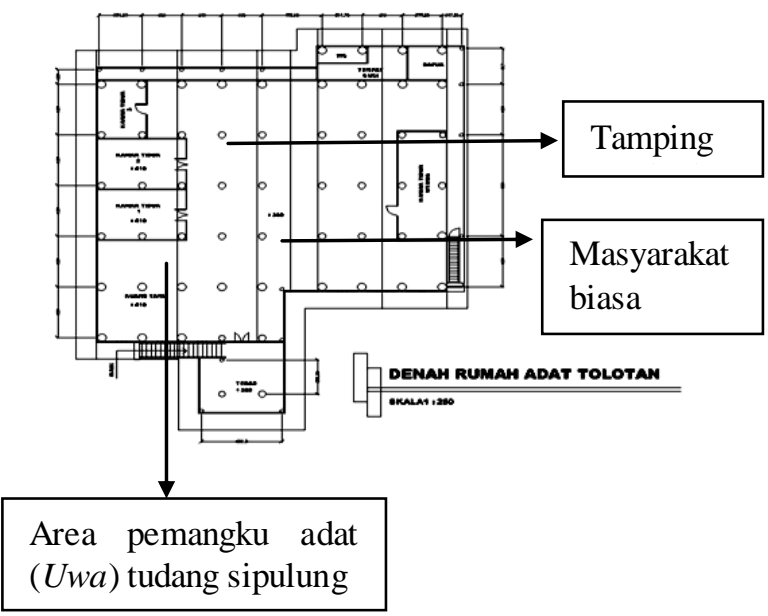

Gambar 3. Denah Rumah Tolotang Sumber: Hasil Survey, 2016

1. Tidak terdapatnya kursi pada rumah Tolotang karena rumah adat menurut tradisi Tolotang tidak diperbolehkan sebab didiami oleh tokoh. Dan rumah adat dianggap sebagai rumah yang suci yang biasa dipergunakan tudang sipulung

2. Tradisi massarapo adalah perluasan rumah kebelakang dan kesamping

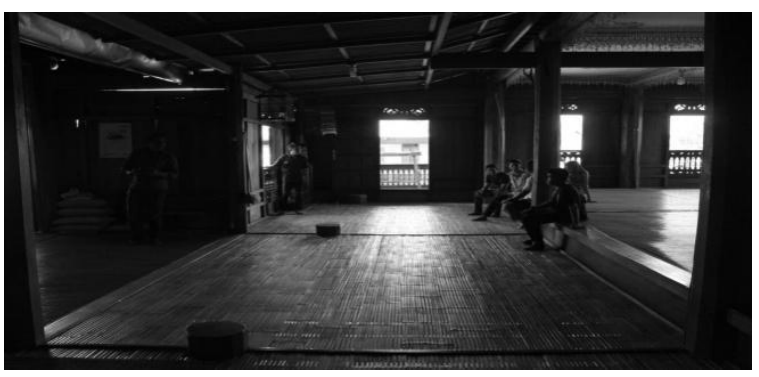

Gambar 4. Entrance Masuk Rumah Adat Sumber: Hasil Survey, 2016

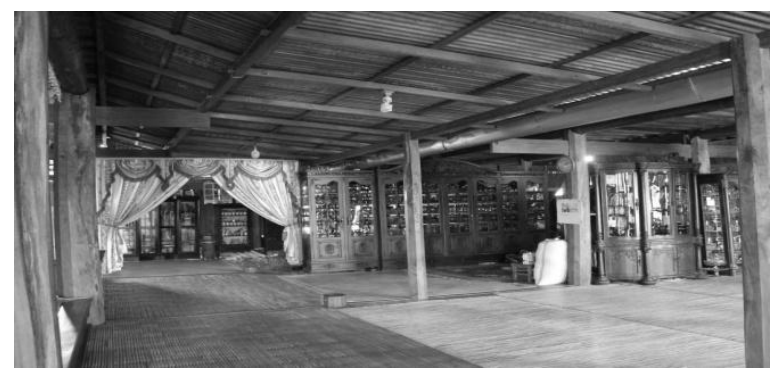

Gambar 5. Tempat Duduk Masyarakat Biasa Sumber: Hasil Survey, 2016

Analisis Pengaruh Sinkretisme Terhadap Pengembangan Fungsi Ruang dan Bentuk Rumah Tinggal Masyarakat Tolotang

Penerapan nilai-nilai sinkretisme pada arsitektur Tolotang secara mikro terlihat pada hubungan antar ruang dan nilai hirarki ruang. Dalam hal ini terdapat ruang ritual:

a. Penerapan pada nilai-nilai sinkretisme pada arsitektur Tolotang secara mikro terlihat pada bubungan antara ruang dan nilai hirarki ruang. dalam hal ini terdapat ruang ritual.

b. Sinkretisme dari segi bentuk rumah Tolotang dipengaruhi oleh sinkretisme budaya Bugis dan agama Islam itu sendiri.

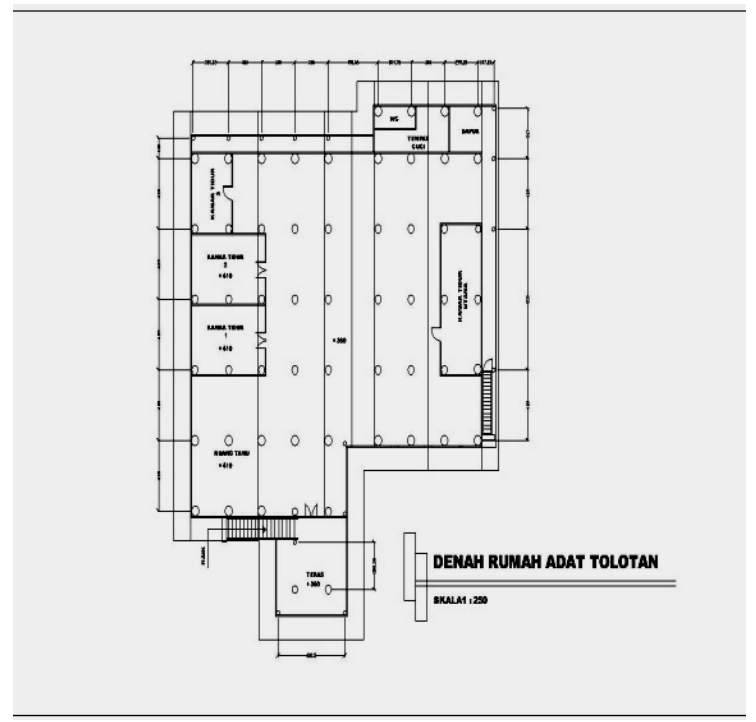

Gambar 6. Denah Rumah Adat Sumber: Hasil Survey, 2016 


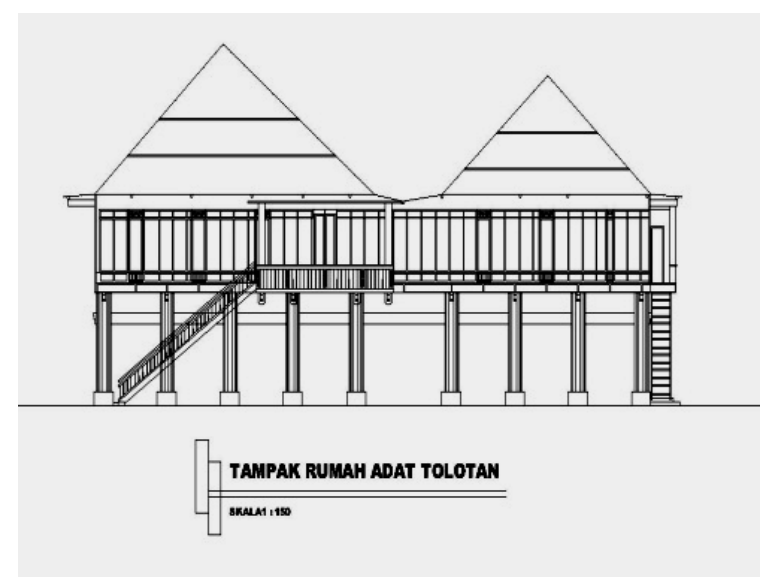

Gambar 6. Ruang ritual

Sumber: Hasil Survey, 2016

Bentuk dasar dari rumah Tolotang itu sendiri berbentuk rumah panggung Bugis. Secara mikro terlihat pada hubungan antar ruang dan nilai hirarki ruang. Rumah adat Tolotang (uwatta) sangat berbeda dengan rumah Tolotang yang lain (masyarakat biasa) sebab hampir $70 \%$ digunakan sebagai tempat melaksanakan upacara ritual dengan demikian salah satu yang menjadi khas rumah tersebut terlihat pada penggabungan dua rumah yang dijadikan satu.

Satu hal yang paling tampak jelas membedakan adalah tiang rumah yang segi delapan dan bundar. Rumah adat punya ciri khusus namun bentuk ini tidak menutup kemungkinan bisa diikuti oleh masyarakat biasa. Semuanya disesuaikan dengan kemampuan. Bentuk tiang yang bulat mempunyai makna yang khusus. Tiang bulat ini diibaratkan bahwa paham Tolotang ini akan kokoh terus dan dipegang teguh dimana tekad komunitas ini bulat dan kuat sepanjang masa.

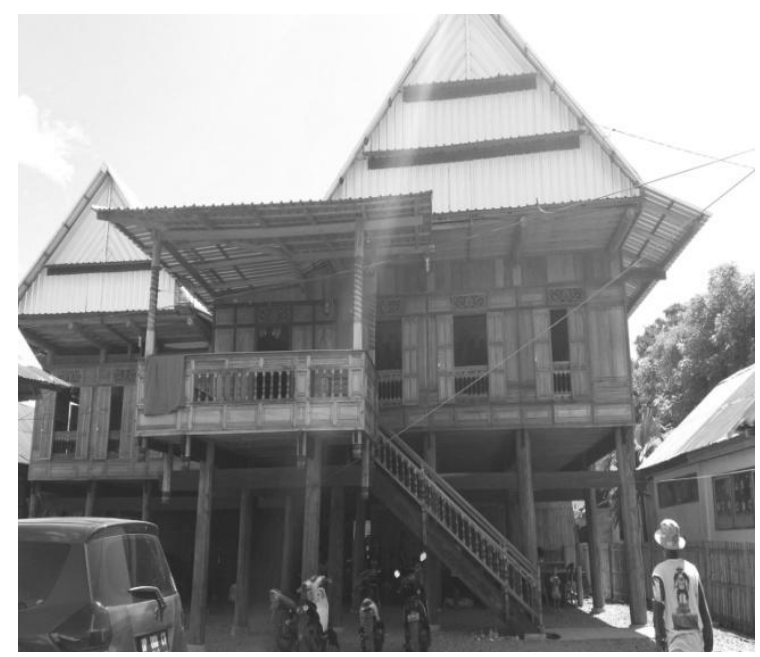

Gambar 8. Foto Rumah Adat Tolotang Sumber: Hasil Survey, 2016

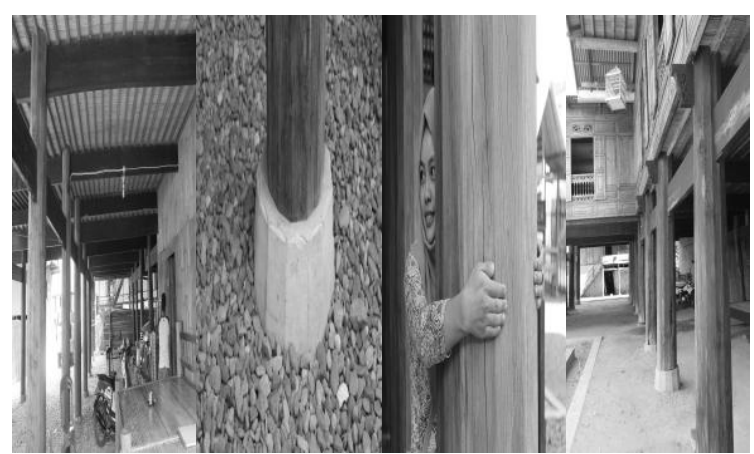

Gbr. 9. Foto Rumah adat Tolotang Dengan Tiang yang Bulat

Sumber: Hasil Survey, 2016

\section{Kesimpulan dan Saran}

\section{Kesimpulan}

a. Manusia tidak dapat dipisahkan dari kebudayaan yang melingkupinya. Kebudayaan akan mempengaruhi setiap tindakan yang mereka ambil. Salah satunya pada saat merancang rumah sebagai perwujudan dari kebudayaan tersebut. Manusia cenderung membentuk rumahnya sesuai dengan kebudayaan mereka karena manusia sebagai penghuni merupakan pengguna atau subjek utama di dalam rumahnya. Hal ini berkaitan erat dengan aktivitas, kebiasaan, kepercayaan, nilai juga norma yang berasal dari kebudayaan asal manusia tersebut.

b. Sinkretisme pada rumah adat Tolotang dipengaruhi oleh kebudayaan Bugis. Bentuk rumah juga dimanefestasikan dengan antropometrik dengan tubuh manusia yaitu atap sebagai atas (kepala), badan sebagai bagian tengah, dan bagian bawah sebagai kaki pada tubuh manusia (Frick,1997). Dengan mengikuti fungsi ruang maka terjadi penggabungan antara 2 rumah dijadikan satu. Sedangkan pada denah hampir $70 \%$ dipergunakan ruang ritual. Sedangkan dengan adanya tamping sebagai pembeda antara pemangku adat dan masyarakat biasa.

\section{Saran}

a. Bagi instasi terkait

Dari hasil penelitian ini diharapkan dapat menjadi informasi bagi instansi yang terkait agar dapat lebih memberikan perhatian terhadap kebudayaan dan penganut kepercayaan yang ada di Sulawesi Selatan. b. Bagi peneliti selanjutnya

Diharapkan menjadi dasar penelitian kebudayaan dan penganut kepercayaan terhadap huniannya c. Bagi Masyarakat

Semoga tingkat pengetahuan masyarakat terhadap kebudayaan dan pemahaman terhadap komunitas masyarakat Tolotang terus meningkat sehingga toleransi antar ummat beragama bisa lebih erat lagi. 


\section{Daftar Pustaka}

- Koentraningrat, 1974, Pengantar Antropologi, Jakarta: Aksara Baru.

- Ratna, Nyoman Kutha, 2005, Sastra dan Kultural Studies: Representase Fiksi dan Fakta. Yogyakarta: Pustaka Pelajar.

- Harris, Marvin, 1999, Theories of Culture in Postmodern Times, New York: Altamira Press.

- Suparlan, Parsudi, 1981/82, "Kebudayaan, Masyarakat dan Agama: Agama Sebagai Sasaran Penenlitian Antropologi”, Majalah ilmu-ilmu sastra Indonesia (Indonesian Journal of Cultural Studies), Juni Jilid X Nomor 1, Jakarta. Fakultas Sastra Universitas Indonesia.

- Laksmi G.S,2008, Makna Arsitektur, Jakarta: Penerbit Universitas Indonesia (UIP).

- John L Esposito., 2000., Dalam Ensiklopedi Oxford Dunia Islam Modern.

- Said.,A.,A., 2004, Simbolisme Unsur Visual Rumah Tradisonal Toraja, Ombak, Yogyakarta.

- Jayadinata, Johara, T., 1999. Tanah Tata Guna Tanah Dalam Perencanaan Pedesaan Perkotaan dalam Wilayah, Edisi 3, Bandung ITB.

- Broadbent, Geoffrey H, 1975, Design In Architecture, John Wiley and Sons Inc, New York.

- Sinkretisme-Wekipedia Bahasa Indonesia, Ensiklopedia bebas dalam https://id.wikipedia.org/wiki/sinkretisme.diakses pada hari Sabtu tanggal 16 juli 2016. Jam 1:08 AM.

- Maria I. Hidayatum, Hakekat Ruang Dalam Arsitektur Tradisonal Sebagai Suatu Bentuk Jawaban Dari Tantangan Alam. Univ. Kristen Petra Surabaya.

- Moh.Yahya Mustafa,. 2006., Tolotang Eksis Ditengah Kepungan Budaya Luar., Kopertis Wilayah IX Sul-Sel. 